\title{
Loss of heterozygosity, by mitotic gene conversion and crossing over, causes strain-specific adenine mutants in constitutive diploid Candida albicans
}

\author{
P. W. K. Tsang, B. Cao, P. Y. L. Siu and J. Wang \\ Author for correspondence: J. Wang. Tel: +8526096122 . Fax: +85226096346. \\ e-mail: b442718@mailserv.cuhk.hk
}

Department of

Biochemistry, Faculty of Medicine, The Chinese University of Hong Kong, Shatin, New Territories, Hong Kong

\begin{abstract}
Molecular evidence is provided in this paper to elucidate a long-standing intriguing phenomenon in fungal genetics: that many natural isolates of the constitutive diploid organism Candida albicans yield strain-specific, recessive mutants at a reproducible frequency that is as high as a few percent of the surviving cells after exposure to UV irradiation or other mutagens. Southern hybridization analysis and DNA sequence data indicated that C. albicans CA12, a clinical isolate, is heterozygous for the ADE2 gene, carrying one functional and one null allele. Sequence analysis of the null allele revealed the presence of a $1.3 \mathrm{~kb}$ deletion, which locates between two AATC repeats and spans the promoter and coding regions of the gene. The adenine auxotrophic mutants, which were readily isolated after UV irradiation of C. albicans CA12, were proved to be the segregants of mitotic recombination as they remained as diploid, not hemizygous or haploid, cells and were homozygous for ade2. Analysis of reciprocal products of the mitotic recombination detected that the process of loss of heterozygosity was mediated by mitotic crossing over (reciprocal exchange of genetic information) as well as gene conversion (nonreciprocal exchange of genetic information).
\end{abstract}

Keywords: Candida albicans, loss of heterozygosity, adenine auxotroph, gene conversion, mitotic crossing over

\section{INTRODUCTION}

Candida albicans, the most common human fungal pathogen, is responsible for the majority of candidiasis (Odds, 1994). This opportunistic pathogen is part of the normal flora in the mouth, vaginal and gastrointestinal tracts in individuals with intact humoral and cellular immunity (Matthews, 1994), but becomes an invasive pathogen in people with a variety of transient or permanent immnocompromised conditions, including transplant recipients, chemotherapy patients, underweight neonates and HIV-infected individuals (Wickes \& Petter, 1996). Molecular genetic, parasexual genetic and biochemical data have demonstrated that the fungus is an obligate diploid (Riggsby et al., 1982; Poulter, 1995), and there is no confirmed report of a haploid cell

Abbreviation : $\mathrm{LOH}$, loss of heterozygosity. or sexual life cycle for the organism. A populationgenetic study based upon isozyme-polymorphism analysis has confirmed that the fungus reproduces by clonal propagation (Pujol et al., 1993). The unique biology and the close relationship between oropharyngeal candidiasis and AIDS development (Coleman et al., 1993) have made the organism one of the current focuses in basic and medical research (Braun \& Johnson, 1997; Corner \& Magee, 1997; Lo et al., 1997; Stoldt et al., 1997; Gale et al., 1998).

It has been observed that many C. albicans natural isolates are prone, after UV or chemical mutagenesis, to yield strain-specific, recessive mutant derivatives at high frequencies (Poulter, 1995). The most common mutant found was auxotrophic for sulfite reduction, followed by mutants auxotrophic for adenine, uracil, cytosine, isoleucine-valine, proline and methionine (Poulter, 1987). Mutants in colony morphology and resistance to 5 -fluorocytosine have also been reported (Defever $e t$ al., 
1982; Poulter, 1987). It has been estimated that at least $10 \%$ of C. albicans isolates exhibit certain types of auxotrophic heterozygosity (Scherer \& Magee, 1990). Based on their extensive genetic studies on UV-induced amino acid auxotrophs in C. albicans FC18, Whelan et al. (1980) hypothesized that the relevant biosynthetic alleles of this strain were indigenously heterozygous, carrying one copy of the wild-type and one copy of the defective allele, and that the mutagenesis promoted mitotic crossing over, resulting in homozygosity of the defective alleles. The auxotrophic heterozygosity is not limited to C. albicans, but has also been recorded in other fungi including Candida parapsilosis (Whelan \& Kwon-Chung, 1988) and Candida krusei (Cao et al., 1997). The physiological significance of natural fungal heterozygosity remains elusive.

In this paper, we report genetic and molecular evidence that (1) the C. albicans clinical isolate CA12 is heterozygous at the $A D E 2$ locus, (2) the strain-specific ade 2 mutants are due to the homozygosis of ade 2 and (3) gene conversion may play a dominant role in the homozygosis of ade2.

\section{METHODS}

C. albicans strains and plasmids. C. albicans clinical isolates CA11, CA12, CA13 and CA14 were all oral isolates recovered from HIV-infected patients in a local hospital and were obtained from Drs D. Tsang (Queen Elizabeth Hospital, Kowloon, Hong Kong) and L. P. Samanarayake (Faculty of Dentistry, University of Hong Kong). C. albicans hOG24 (ade1 pro1 met1; Poulter \& Rikkerink, 1983) and hOG300 (ade2 pro1 met1; Kurtz et al., 1987), plasmids pRC2231 (Cannon et al., 1992) and pSM7 (Kurtz et al., 1986) were obtained from Dr R. D. Cannon (University of Otago, New Zealand).

UV mutagenesis and isolation of fungal sectors. Yeast cells in their early-exponential phase were spread onto the surface of YM plates $\langle 0.3 \%$ yeast extract, $0.3 \%$ malt extract, $0.5 \%$ peptone, $1 \%$ glucose and $2 \%$ agar) at a density of approximately $10^{6}$ cells per plate $(15 \mathrm{~cm}$ diameter $)$ and were immediately exposed to UV light for $75 \mathrm{~s}$ at a distance of $60 \mathrm{~cm}$, equivalent to a dosage of $0 \cdot 180 \mathrm{~mW} \mathrm{~cm}^{-2} \mathrm{~s}^{-1}$ as measured by an IL1430 health-hazard radiometer (International Light). Ade ${ }^{-}$auxotrophs appeared as red-coloured colonies or colony sectors on YM plates after $3-4 \mathrm{~d}$ incubation at $37^{\circ} \mathrm{C}$. The white sectors of the sectored fungal colonies were purified as follows : individual white sectors were recovered from the YM plate as completely as possible and transferred into $1 \mathrm{ml}$ water using a sterilized transfer needle or a flat tooth pick. Care was taken to avoid contamination from the red sectors. Aliquots of the fungal suspension were spread on YM plates after briefly vortexing the suspension to mix the cells. Single white colonies were randomly chosen for further genetic analysis.

Parasexual analysis. The procedure of protoplast fusion was essentially as described by Sarachek et al. (1981). The test strains were C. albicans hOG24 (ade1 pro1 met1) and hOG300 (ade2 pro1 met1). Two partner fungal cells were grown separately in $20 \mathrm{ml}$ YM until the $\mathrm{OD}_{600}$ reached 1.0 . After harvesting by centrifugation at $1500 \mathrm{~g}$ for $5 \mathrm{~min}$, the cell pellets were washed twice with sterile distilled water, resuspended in $2 \mathrm{ml}$ PC solution $(0.1 \mathrm{M}$ phosphate, $0.05 \mathrm{M}$ citrate buffer, $\mathrm{pH} 5 \cdot 3$, containing $1 \% \beta$-mercaptoethanol) and rotated at 160 r.p.m. on an orbital shaker at $37^{\circ} \mathrm{C}$ for $30 \mathrm{~min}$. The cells were then washed twice with $10 \mathrm{ml} \mathrm{KB}$ solution $(0.6 \mathrm{M}$ $\mathrm{KCl}$ in $0.1 \mathrm{M}$ phosphate, $0.05 \mathrm{M}$ citrate buffer, $\mathrm{pH} 5.3$ ), resuspended in $2 \mathrm{ml} \mathrm{KB}$ solution and $120 \mu$ lyticase solution (10 $\mathrm{mg} \mathrm{ml}^{-1}$, Sigma, in KB solution). The enzyme mixture was incubated at $37^{\circ} \mathrm{C}$ for $15-30 \mathrm{~min}$ at 160 r.p.m., washed with $3 \mathrm{ml} \mathrm{KB}$ solution, resuspended in $5 \mathrm{ml}$ fusion mix $140 \% \mathrm{PEG}$ $3350,10 \mathrm{mM} \mathrm{CaCl})_{2}$ ) and incubated at $37^{\circ} \mathrm{C}$ at 160 r.p.m. for $30 \mathrm{~min}$. The cell pellets were collected by centrifugation, resuspended in $800 \mu \mathrm{l} \mathrm{KBC}$ solution $(0.6 \mathrm{M} \mathrm{KCl}$ and $10 \mathrm{mM}$ $\mathrm{CaCl}_{2}$ in $0.1 \mathrm{M}$ phosphate, $0.05 \mathrm{M}$ citrate buffer, $\mathrm{pH} 5.3$ ) and spread onto GSB plates [1.5\% glucose, $0.1 \%$ ammonium sulfate, $0.2 \%$ potassium dihydrogen phosphate, $0.005 \%$ magnesium sulfate, $0.005 \%$ calcium chloride, $0.001 \%$ biotin and $1.5 \%$ agar (Noble)], supplemented with $1 \mathrm{M}$ sorbitol. The fusion products appeared as white colonies on the plates after $3-4 \mathrm{~d}$ incubation at $37^{\circ} \mathrm{C}$.

Isolation and sequencing of the $A D E 2$ gene. $P C R$ reaction mixtures $(50 \mu \mathrm{l})$ for amplification of $A D E 2$ and ade 2 contained $1-5 \mathrm{ng}$ fungal genomic DNA, $10 \mathrm{ng}$ each of two primers, $\mathrm{P} 9$ (5'-CTT GAC GAA AAC TGA ATT TAT TCA C-3') corresponding to nucleotide position 9-33 and CR2244 (5' CTA TTT TTT CAA TTT ATC AGT TAA-3') corresponding to position 2221-2244 of the ADE2 gene (Genbank accession no. U75582), 0.2 mM dNTP, PCR buffer $(10 \mathrm{mM}$ Tris/ $\mathrm{HCl}, \mathrm{pH} 8.3,50 \mathrm{mM} \mathrm{KCl}$ and $1.5 \mathrm{mM} \mathrm{MgCl}_{2}$ ) and 2.0 units $\mathrm{T} a q$ DNA polymerase. Reactions were carried out under the following conditions: $94^{\circ} \mathrm{C}, 1 \mathrm{~min} 30 \mathrm{~s} ; 56^{\circ} \mathrm{C}, 1 \mathrm{~min} 30 \mathrm{~s}$; $72^{\circ} \mathrm{C}, 2 \mathrm{~min} 15 \mathrm{~s}$ for 35 cycles. The DNA template was denatured for $2 \mathrm{~min}$ at $100^{\circ} \mathrm{C}$ before it was mixed with the polymerase. After PCR and gel electrophoresis, the desired PCR fragment was excised and purified using a GeneClean II kit (BIO 101). Purified PCR products were cloned into pCRII, and sequenced using a T7 Sequencing Kit (Pharmacia Biotech). Nucleotides of the gene are numbered as described in the Genbank entry with the first nucleotide of the starting codon at position 541 .

Hybridization probe. A $2 \cdot 2 \mathrm{~kb}$ PCR fragment was amplified from C. albicans CA12 using primers P9 and CR2244 and cloned into pCRII (Invitrogen) to generate plasmid pCBY101. A $2.2 \mathrm{~kb} K p n \mathrm{I}-E c o \mathrm{RV}$ fragment from pCBY101 containing the $A D E 2$ gene was used as the $A D E 2$ probe in hybridization experiments.

C. albicans DNA transformation. DNA transformation was performed as described by Goshorn et al. (1992) with minor modifications. A $2.2 \mathrm{~kb}$ PCR fragment containing DNA sequence from position 59-2244 of the ADE2 gene was amplified using primers P59 (5'-ATG GTT AAT ATT TTT GCT TGA TGA T-3'), corresponding to nucleotide position 59-83, and primer CR 2244. The PCR fragment was purified from an agarose gel and used for the transformation. Fungal protoplasts were prepared by digesting exponential-phase fungal cells with lyticase for $1 \mathrm{~h}$ at $37^{\circ} \mathrm{C}$. One hundred microlitres of protoplast suspension was mixed with $10 \mu \mathrm{g}$ transforming DNA, together with $40 \mu \mathrm{g}$ calf thymus DNA as carrier, and incubated at room temperature for $15 \mathrm{~min}$. Afterwards, $800 \mu \mathrm{l} 40 \%$ PEG 3350 in $10 \mathrm{mM} \mathrm{CaCl}_{2}$ was added, incubated at room temperature for $15 \mathrm{~min}$, and mixed with $5 \mathrm{ml}$ soft agar [containing GSB medium, $1 \mathrm{M}$ sorbitol and $0.8 \%$ agar (Noble)], and poured onto GSB agar plates. Transformants were scored after $3 \mathrm{~d}$ incubation at $37^{\circ} \mathrm{C}$. The transformation frequency was 5-10 transformants per microgramme of PCR DNA. 


\section{RESULTS}

\section{Generation of ade2 mutants from C. albicans CA12 by UV irradiation}

C. albicans, Saccharomyces cerevisiae and Ustilago maydis ade 2 or ade1 mutants appear as red colonies on media deficient in adenine (Silver \& Eaton, 1969; Poulter et al., 1981; Kronstad et al., 1989). After screening four C. albicans isolates (CA11, CA12, CA13 and CA14) isolated from local HIV-infected patients, we found that one of them, C. albicans CA12, consistently gave rise to such red adenine auxotrophs at a frequency of $2-6 \%$ of the surviving cells following UV irradiation as specified in the Methods. Two thousand surviving cells were randomly selected and replica plated on YM agar, a complete medium, and GSG agar, a minimal medium, and no auxotrophic mutants other than the red adenine mutants were detected. The three other C. albicans strains including CA11 were also subjected to the same UV treatment but no red $\mathrm{Ade}^{-}$mutants were detected. No spontaneous red adenine auxotroph was detected among more than 100000 CA12 cells. Protoplasts were prepared from the $\mathrm{Ade}^{-}$derivatives of CA12 and fused individually with the protoplasts of C. albicans hOG24 (ade1 pro1 met1; Poulter \& Rikkerink, 1983) and hOG300 (ade2 pro1 met1; Kurtz et al., 1986). All the $\mathrm{Ade}^{-}$derivatives of CA12 tested formed fusants, which grew as white colonies on GSG plates, with hOG24, but not with hOG300. The adenine mutants were also rescued by transformation of integrative plasmid pSM7 (Kurtz et al., 1986) or self-replicating plasmid pRC2231 (Cannon et al., 1992), both of which carry the C. albicans $A D E 2$ gene.

\section{C. albicans CA12 carries natural heterozygosity at ADE2}

Genomic DNA was extracted from CA12 and CA11, as well as from two of the randomly selected ade 2 derivatives of CA12, termed CA12-1-R1 and CA12-1$\mathrm{R} 2$, digested with EcoRV and probed with the cloned $2 \cdot 2 \mathrm{~kb} K p n \mathrm{I}-E c o \mathrm{RV}$ fragment containing the C. albicans $A D E 2$ gene (Methods). The genomic Southern analysis (Fig. 1) shows that a $2.7 \mathrm{~kb}$ EcoRV band, which contains the entire C. albicans ADE2 gene (Fig. 2a) (Kurtz et al., 1986), is present in CA11 and CA12 (Fig. 1, lanes 1 and 2), but is absent in the ade2 mutants CA12-1-R 1 and CA12-1-R2 (lanes 3 and 4) A smaller band of $1.4 \mathrm{~kb}$ in size, is detected in CA12, CA12-1-R1 and CA12-1-R2 (lanes 2, 3 and 4), but not in CA11 (lane 1). These results suggested that CA12, in contrast to CA11, was heterozygous at $A D E 2$, and that the ade 2 derivatives of CA12 had lost ADE2 heterozygosity.

To determine the location of the deletion in the mutant ade 2 allele in CA12, two PCR products of 2.2 and $0.9 \mathrm{~kb}$ in size were amplified using CA12 genomic DNA as a template and oligonucleotides P9 (corresponding to nucleotide position 9-33 of the ADE2 gene) and CR2244 (corresponding to nucleotide position 2221-2244 of the $A D E 2$ gene) as primers (data not shown). The two

\begin{abstract}
$\begin{array}{llllllllll}1 & 2 & 3 & 4 & 5 & 6 & 7 & 8 & 9 & 10\end{array}$

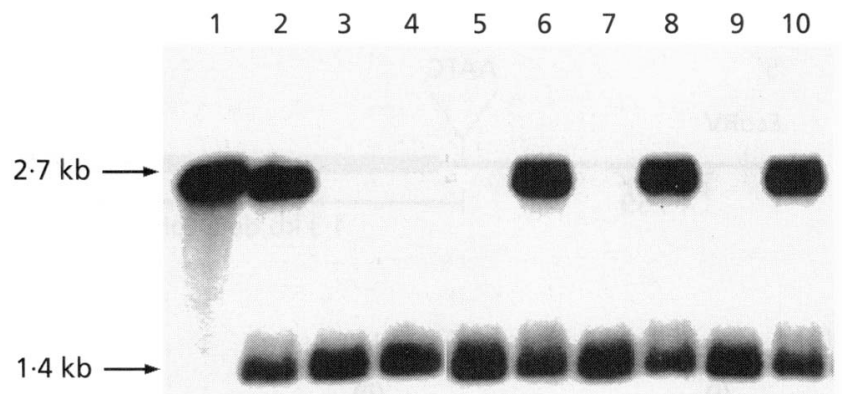

Fig. 1. Southern analysis of $C$. albicans $C A 12$ and its adenine auxotrophic derivatives (lanes 1-4) and the prototrophic transformants of ade2 mutants (lanes 5-10). Lane 1, C. albicans CA11; lane 2, C. albicans CA12; lane 3, ade2 auxotroph CA12-1R1 and lane 4, ade2 auxotroph $C$. albicans CA12-1-R2; lanes 5 and 6, CA12-1-R1 and its prototrophic transformant, CA12-1-R1$\mathrm{T} 1$; lanes 7 and 8, CA12-1-R2 and its prototrophic transformant, CA12-1-R2-T1; lanes 9 and 10, CA12-2-R1 and its prototrophic transformant, CA12-2-R1-T1. Note the reappearance of the $2.7 \mathrm{~kb}$ EcoRV fragment in the transformants (lanes 6, 8 and 10). The fungal DNA was digested with ECORV and probed with the $2 \cdot 2 \mathrm{~kb} K$ pnl-EcoRV fragment that contains the entire $C$. albicans $A D E 2$ gene.
\end{abstract}

primers were chosen as their PCR product covers almost the entire ADE2 gene (Fig. 2a). The $1.3 \mathrm{~kb}$ size difference between the two products matched exactly the size difference between the two homologous EcoRV bands displayed in the genomic Southern blot shown in Fig. 1. The two PCR products were cloned into pCRII and sequenced. The larger PCR product carried the wildtype gene $A D E 2$, as its sequence is $99.60 \%$ identical (2239 out of $2248 \mathrm{bp}$ ) to that of ADE2 in C. albicans SC5314. The DNA sequence of the smaller PCR product was almost identical to that of $A D E 2$ but contained a $1.3 \mathrm{~kb}$ deletion between positions 490 and 1764 of the $A D E 2$ gene. The small PCR product was therefore determined to carry the null allele ade 2 . The $1.3 \mathrm{~kb}$ deletion spans the promoter and coding regions of the gene, between the two AATC repeats (Fig. 2b). Besides, the DNA sequence of ade 2 differed from that of $A D E 2$ by three transition mutations at the $5^{\prime}$ promoter region: a $\mathrm{C} \rightarrow \mathrm{T}$ at position 281 , a $\mathrm{T} \rightarrow \mathrm{C}$ at position 346 and an $A \rightarrow G$ at position 413 . These sequence polymorphisms provided an additional way to distinguish the two alleles.

\section{Adenine mutants are homozygous diploid at ade2}

The loss of ADE2 heterozygosity in the ade 2 mutants could be due to (1) de novo deletion of approximately $1.3 \mathrm{~kb}$ of the $A D E 2$ gene; (2) haploidization; (3) aneuploidic loss of $A D E 2$; or (4) homozygosis at ade 2 (ade2/ade2) by mitotic recombination (Fig. 3). Using the PCR primers P9 and CR2244, ade 2 alleles were amplified from three independent ade 2 mutants of CA12, termed CA12-1-R1, CA12-1-R2 and CA12-1-R4, and cloned 
(a)

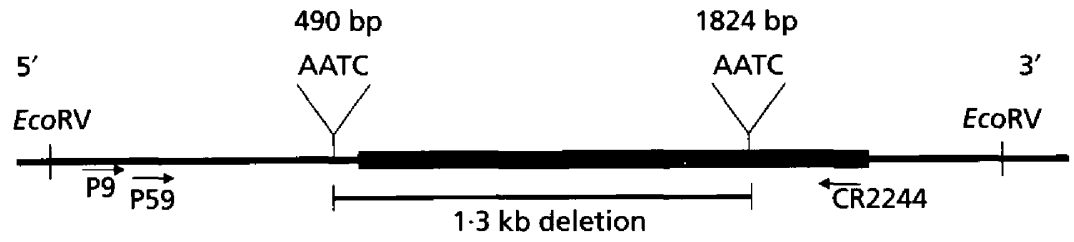

(b)

(i)

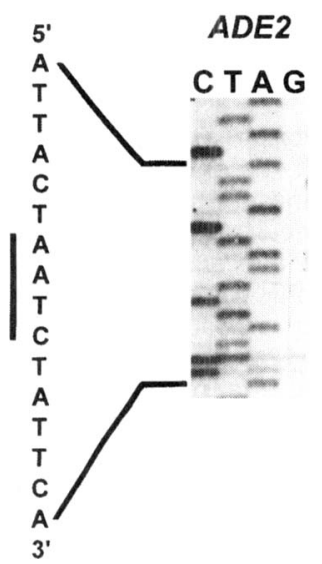

(ii)

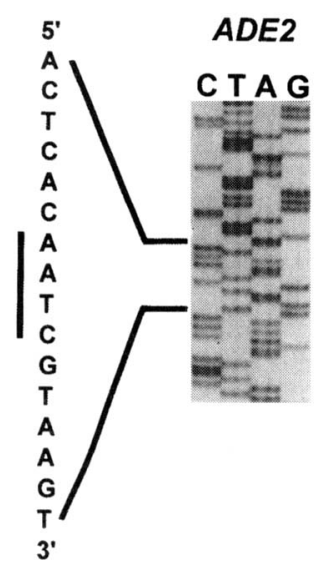

(iii)

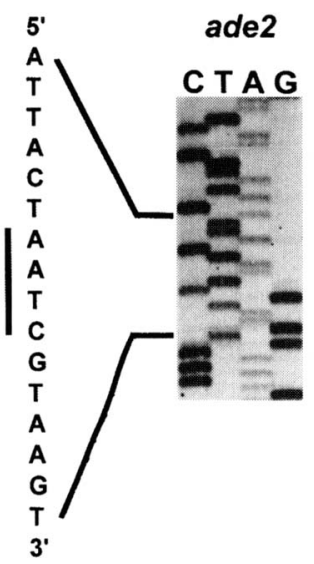

Fig. 2. (a) Map of the ADEZ gene. The 5' AATC corresponds to nucleotide position 490-493 and the 3' AATC corresponds to nucleotide position 1824-1827 of the gene. The ORF, marked as a thick black box, runs from nucleotide position 541 to 2244 . The direction and positions of the primers used in the study and EcoRV restriction sites are also shown. (b) The ADE2 and ade2 DNA sequences flanking the $1.3 \mathrm{~kb}$ deletion. (i) $A D E 2$ DNA sequence at the $5^{\prime}$ end of the deletion. The $5^{\prime}$ A corresponds to position 490 of the gene. (ii) $A D E 2$ DNA sequence at the $3^{\prime}$ end of the deletion. The $5^{\prime}$ A corresponds to position 1824 of the gene. (iii) ade2 DNA sequence at the border regions of the deletion. The AATC is marked with a vertical bar. into pCRII. Two clones from each of the mutants were sequenced. The DNA sequences of the six clones were identical to each other and to that of ade 2 of CA12 (data not shown), suggesting that none of the $a d e 2$ mutants was due to novel deletion of $A D E 2$ and they all originated from the null ade 2 allele in CA12.

PCR fragment P59-CR2244, corresponding to nucleotide position 59-2244 of the ADE2 gene, was amplified using primers P59 and CR2244, and was used to transform adenine auxotrophs CA12-1-R1 and CA12-1$\mathrm{R} 2$. This PCR fragment is $2 \cdot 2 \mathrm{~kb}$ in size and contains the missing $1.3 \mathrm{~kb}$ DNA sequence (Fig. 2a). The PCR fragment was introduced into the protoplasts of the recipient strains using the $\mathrm{CaCl}_{2}-\mathrm{PEG}$ method and the prototrophic transformants were selected on minimal medium free of adenine. One prototrophic transformant each was randomly chosen from the transformants of CA12-1-R1, CA12-1-R2 and CA12-2-R1, their DNA was extracted, digested with $E c o R V$ and probed with the $2.2 \mathrm{~kb} A D E 2$ fragment. It is evident that the recipients CA12-1-R1, CA12-1-R2 and CA12-2-R1 (Fig. 1 , lanes 5,7 and 9) contain only the $1.4 \mathrm{~kb}$ fragment; while all of the three corresponding transformants CA12-1-R1-T1, CA12-1-R2-T1, and CA12-2-R1-T1 contain the $2.7 \mathrm{~kb}$ EcoRV fragment present in the parental CA12 cells (Fig. 1, lanes 6, 8 and 10), as well as the $1.4 \mathrm{~kb}$ fragment. The $1.4 \mathrm{~kb}$ fragment would be absent if these $\mathrm{Ade}^{+}$transformants were aneuploids containing only one copy of ade2. Our data can be best explained that the ade 2 recipients contain two copies of ade 2 and the transforming DNA has converted one of them to $A D E 2$ by, presumably, homologous recombination. The restored $A D E 2$ heterozygosity in the transformants was also confirmed; the three $\mathrm{Ade}^{+}$ transformants were also prone to the generation of adenine mutants, as was their parental strain CA12, after UV irradiation (data not shown).

CA12-1-R1 and CA12-1-R2 were treated by UV mutagenesis and the surviving cells were transferred to adenine-supplemented minimal medium and YM medium by replica plating, to screen for additional auxotrophic mutants. We failed to detect any additional auxotrophs among the 3000 surviving cells screened. The detection of other auxotrophs was expected if these mutants were haploid cells (Fig. 3, path V). Based on the above data we conclude that the UV-induced adenine mutants are homozygous diploid at ade2.

\section{Both gene conversion and mitotic crossing over are responsible for the loss of ADE2 heterozygosity}

After UV irradiation, many of the $\mathrm{Ade}^{-}$derivatives of CA12 appeared as a red sector in an otherwise white colony, the white being composed of prototrophic cells. Two methods, UV mutagenesis and genomic Southern analysis, were used to examine the genotype of cells purified from the white sectors. Some of the cells derived from the white sectors such as CA12-1-W2 and CA12-2W6 were no longer prone to the formation of $\mathrm{Ade}^{-}$ mutants by UV irradiation (data not shown). Genomic Southern analysis demonstrated that CA12-1-W2 and CA12-2-W6 had lost ade2 and only contained ADE2 


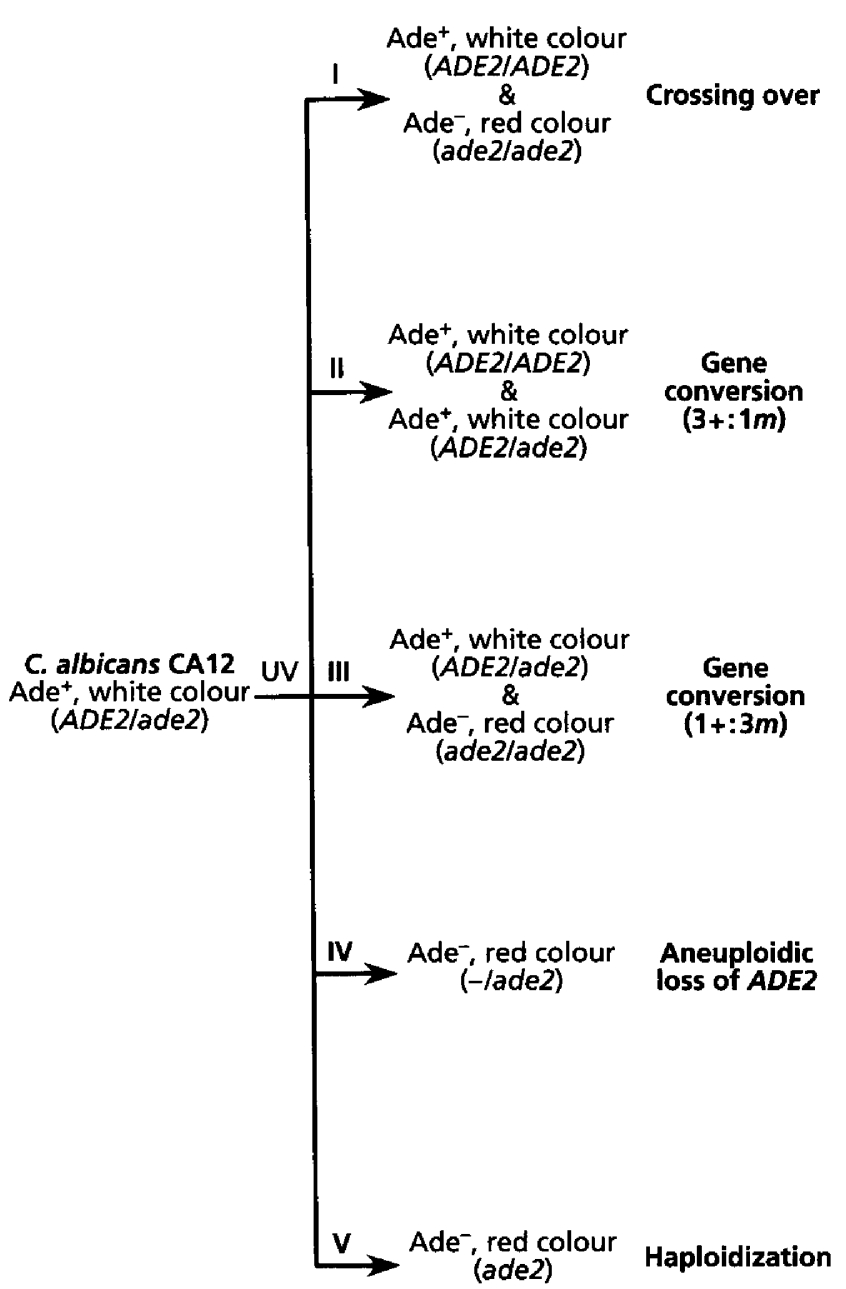

Fig. 3. Five possible genetic rearrangements of $A D E 2 / a d e 2$ heterozygotes. Path I refers to mitotic crossing over; path II, $3+: 1 \mathrm{~m}$ gene conversion, the non-reciprocal transfer of genetic materials; path III, $1+: 3 m$ gene conversion; path IV, aneuploidic loss of $A D E 2$; and path $V$, haploidization. The sibling segregants are grouped together with the sign \&. (-lade2) refers to an ade2 hemizygote. + , wild-type; $m$, mutant.

(Fig. 4, lanes 4 and 8). This indicated that these white prototrophic sectors were $A D E 2 / A D E 2$ and were the progenies of one of the two sibling cells of the mitotic crossing over; the other sibling cell, the reciprocal product of the crossing over, was the red auxotrophic carrying the ade2/ade 2 alleles (Fig. 3, path I).

However, among the 108 white sectors tested, only 50 lost their ability to produce adenine mutants. The remaining 58, exemplified by CA12-1-W1 and CA12-2W1, maintained their ability to continuously segregate into ade 2 mutants at frequencies similar to that of the parental strain CA12 upon UV irradiation (data not shown). Southern analysis verifies that the cells from these white sectors carry the same genotype as CA12, ie $A D E 2 / a d e 2$, as displayed by the existence of the large EcoRV fragment characteristic of ADE2 and the small

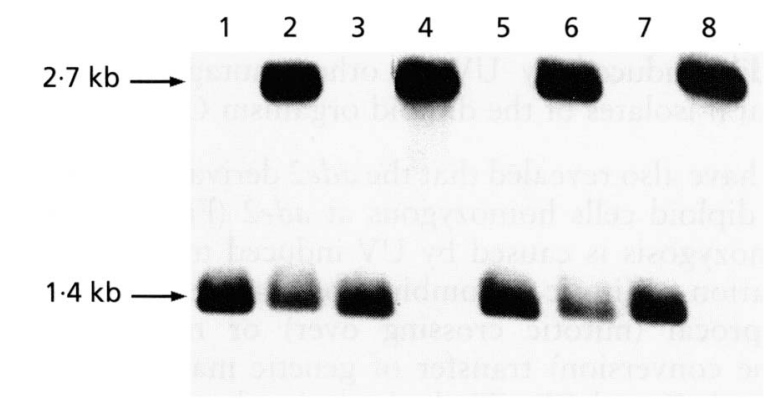

Fig. 4. Southern analysis of the genotypes of the white sectors in the red/white twin-sectored colonies. Lanes 1 and 2, CA12-1R1 and its sibling prototrophic white sector, CA12-1-W1; lanes 3 and 4, CA12-1-R2 and its sibling prototrophic white sector, CA12-1-W2; lanes 5 and $6, C A 12-2-R 1$ and its sibling prototrophic white sector, CA12-2-W1; lanes 7 and 8, CA12-2-R6 and its sibling prototrophic white sector, CA12-2-W6. Southern analysis was done as described in Fig. 1.

EcoRV fragment characteristic of ade 2 in the two isolates (Fig. 4, lanes 2 and 6). Since the other sibling cell of the recombination was the red auxotroph with the genotype ade2/ade2, our results indicated the occurrence of the non-Mendelian, $1+: 3 m$ ( + , wild-type; $m$, mutant) segregation of heterozygous $A D E 2$ alleles between the two sibling cells of CA12 in these white/red sectored colonies. Such non-reciprocal transfer of genetic information is a typical characteristic of gene conversion (Fig. 3, path III).

\section{DISCUSSION}

In dissection of the genetic mechanism underlining natural fungal heterozygosity, C. albicans CA12 offers several experimental conveniences: (1) the red, adeninerequiring auxotrophic mutants are visually identifiable on media deficient in adenine; (2) the gene, $A D E 2$, has a defined biochemical function, encoding phosphoribosylaminoimidazole carboxylase in the de novo purine biosynthetic pathway; (3) both integrative and selfreplicating plasmid transformation systems are available for the rescue of ade2 mutants (Kurtz et al., 1987; Cannon et al., 1992); (4) because of the presence of the large deletion at ade2, the wild-type and the defective allele are easily distinguishable by PCR or Southern analysis; and (5) the ADE2 DNA sequence has been determined (Tsang et al., 1997).

We have demonstrated that the $A D E 2$ locus of $C$. albicans CA12 is heterozygous (ie ADE2/ade2). The null allele, ade2, has lost a $1.3 \mathrm{~kb}$ fragment in the promoter and coding regions of the gene as the result of a deletion between the two AATC repeats (Fig. 2). Our data clearly indicate that the natural heterozygosity at $A D E 2$ forms the genetic basis for the high frequency of the specific auxotrophic phenotype in CA12 (Fig. 1), and that the loss of heterozygosity ( $\mathrm{LOH}$ ) at $A D E 2$ in $C$. albicans CA12 leads to the generation of ade 2 mutants (Fig. 1). This has, therefore, for the first time provided a molecular explanation for one of the puzzles in my- 
cology: how strain-specific, recessive mutants can be readily induced by IIV or other mutagens in many natural isolates of the diploid organism $C$. albicans.

We have also revealed that the ade 2 derivatives of $\mathrm{CA} 12$ are diploid cells homozygous at ade2 (Fig. 1) and the homozygosis is caused by UV-induced mitotic recomhination. Mitotic recombination can lcad to cither reciprocal (mitoric crossing over) or non-reciprocal (gene conversion) transter of genetic material (Fig. 3, paths I, II and III). We had previously suggested that gene conversion is onc of the mechanisms for the generation of adenine mutants in C. krusei (Cao et al., 1997). [n the present study, our genetic analysis of the whice prototrophic sectors in the red/white sectored colonies has furnished revealing information on the pathways of mitotic recombination. Two classes of the white prototrophic sectors were detected. The first class, which was previously called mitotically stable prototrophic strains (Poulter et al., 1981), were no longer able to further segregate to give ade 2 auxotrophs and were homozygous at the ADE2 locus. This type of red/white sectored colony is most likely the consequence of the mitotic crossing over (Fig. 3, path I). The second class of the white protorrophic sectors occurred more often. They remained prone to produce UV-induced ade2 mutants and were hererozygous at ADE2 (Fig. 3, path III). These white sectors were certainly not due to contamination of un-mutagenized cells grown next to the sectored colonies as we failed to derect the existence of the mixed population of $A D E 2 / A D E 2$ and $A D E 2 /$ ade. 2 in more than 30 white sectors examined (data not shown: We theretore conclude the existence of two pathways of mitotic recombination in C. albicans C.A12: crossing over and gene conversion.

Our data support the basic tenets of the natural heterozygosity hypothesis (Whelan et al, 1980) and furthermore indicate, based upon the frequent occurrence of $1+: 3 m$ segregation of $A D E 2$, that gene conversion may play an important role in the LOII of $A D E 2$. The actual contribution of genc conversion to the mitotic recombination is likely to be underestimated since the current investigation does not include the $3+: 1 m$ gene conversion of $A D E 2$. Both of the reciprocal progenies of the $3+: 1 m$ gene conversion are white protocrophic cells, but one with a genotype of $A D E 2 /$ ADE2 and the other ADF.2/ade2 (Fig. 3, path 1I). In addition, the method we used for the detecrion of ADE2/ade2 heterozygotes, ie screening the red colonies after UV mutagenesis, was not a sensitive one and may have missed some of the mutants.

The frequency of $\mathrm{LOH}$ of the $A D E 2$ under natural conditions is unknown but is expected to be low, for we did not detect any sponcaneous red adenine mutants from CA 2 in the absence of UV treatment. It remains to be examined whether any other chemical or physical agents may promote the LOH more efficiencly than UV irradiation; or whether $\mathrm{LOH}$ of some genes may lead to the generation of mutants that are favourably selected under certain living environments.
We have noticed that the $1.3 \mathrm{~kb}$ deletion occurs between two A A TC repeats (Fig. 2). It would be unwise to simply ignore the phenomenon as a fortuitous event, but it is cqually difficult to argue that the A A TC repeats provide sufficicnt cis-acting information for site-specific tecomhination, as numerous copies of the retranucleotide arc interspersed throughout the C. albicans genome. Additional experiments are required to prove or disprove the significance of the phenomenon.

C. albicans, like numerous other imperfect fungi, is an obligate diploid organism. Many evolutionary advantages such as biodiversity and hybrid vigour granted by meiosis are denied to these fungi. It has long heen suggested that $C$. albicans relies upon certain unique genetic processes, such as heritable phenotypic variation (also called phenotypic instability or swirching) associated with colony morphology (Slutsky et al., 1985) and ploidy change (Suzuki et al., 1982; Janbon et al., 1998: to compensate for its intrinsic genetic deficiency. The frequent detection of $\mathrm{C}$. albicans natural isolates wirh a wide spectrum of recessive heterozygosity (Poulter, 1987) may be an unfortunate consequence of the absence of meiosis in the fungus, as mitotic recombination is a much slower process of removing mutant alleles. Alecrnatively, the natural heterozygosity may serve as yet another vehicle by the organism to elevate its genetis variability. It will be interesting and worthwhile to test the competitiveness of strains hererozygous at $A D E 2$ over their corresponding isogenic strains homozygous at the locus. It is out hope that the full comprehcnsion of the phenomenon of fungal natural heterozygosity does not just satisfy academic curiosity, but also provides useful information that may guide (C. albicans geneticists to design alternacive approaches to creare desired mutations in this ohligare diploid.

\section{ACKNOWLEDGEMENTS}

P. W. K. Tsang and $\mathrm{B}$. Cao contributed equally to this work. We thank Drs D. Tsang and L. P. Samanarayake for $C$. albicans strains: Dr R. D. Cannon for plasmids pRC2231 and pSM?, C. albicans strains hOG24 and hOG300; Dr C. B. Hazlert for helpful comments; Dr D. C. Colcman and two anonymous referees for constructive criricisms and the University Grants Commirtee of the Hong Kong Special $\Lambda$ dministrative Region of PRC for financial support.

\section{REFERENCES}

Braun, B. R. \& Johnson, A. D. (1997). Control of filament formation in Candida albiaans by the transcriptional repressor TUP1. Science 277, 105-109.

Cannon, R. D., Jenkinson, H. F. \& Shepherd, M. G. (1992). Cloning and expression of Candida sibicans $A D E 2$ and proteinase genes on a replicative plasmid in C: albicans and in Sacharomyces cerevisiae. Mol Gen Gene' 235, 453-457.

Cao, B., Tsang, P. W. K., Wu, T., Samaranayake, L. P. \& Wang, J. (1997). Adenine auxotrophic heterozygosity in Cundida krusei. I Med Vet Mycol 35, 33-36.

Coleman, D. C., Bennett, D. E., Sullivan, D. J., Gallagher, P. J., Henman, M. C., Shanley, D. B. \& Russell, R. J. (1993). Oral 
Candida in HIV infection and AIDS: new perspectives/new approaches. Crit Rev Microbiol 19, 61-82.

Corner, B. E. \& Magee, P. T. (1997). Candida pathogenesis: unraveling the threads of infection. Curr Biol 7, 691-694.

Defever, K. S., Whelan, W. L., Rogers, A. L., Beneke, E. S., Veselenak, J. M. \& Soll, D. R. (1982). Candida albicans resistance to 5 -fluorocytosine: frequency of partially resistant strains among clinical isolates. Antimicrob Agents Chemother 22, 810-815.

Gale, C. A., Bendel, C. M., McClellan, M., Hauser, M., Becker, J. M., Berman, J. \& Hostetter, M. K. (1998). Linkage of adhesion, filamentous growth, and virulence in Candida albicans to a single gene, INT1. Science 279, 1355-1358.

Goshorn, A. K., Grindle, S. M. \& Scherer, S. (1992). Gene isolation by complementation in Candida albicans and applications to physical and genetic mapping. Infect Immun 60, 876-884.

Janbon, G., Sherman, F. \& Rustchenko, E. (1998). Monosomy of a specific chromosome determines L-sorbose utilization: a novel regulatory mechanism in Candida albicans. Proc Natl Acad Sci USA 95, 5150-5155.

Kronstad, J. W., Wang, J., Covert, S. F., Holden, D. W., McKnight, G. L. \& Leong, S. A. (1989). Isolation of metabolic genes and demonstration of gene disruption in the phytopathogenic fungus Ustilago maydis. Gene 79, 97-106.

Kurtz, M. B., Cortelyou, M. W. \& Kirsch, D. R. (1986). Integrative transformation of Candida albicans, using a cloned Candida ADE2 gene. Mol Cell Biol 6, 142-149.

Kurtz, M. B., Cortelyou, M. W., Miller, S. M., Lai, M. \& Kirsch, D. R. (1987). Development of autonomously replicating plasmids for Candida albicans. Mol Cell Biol 7, 209-217.

Lo, H. J., Köhler, J. R., DiDomenico, B., Loebenberg, D., Cacciapuoti, A. \& Fink, G. R. (1997). Nonfilamentous C. albicans mutants are avirulent. Cell 90, 939-949.

Matthews, R. C. (1994). Pathogenicity determinants of Candida albicans: potential targets for immunotherapy? Microbiology 140, 1505-1511.

Odds, F. C. (1994). Candida albicans, the life and times of a pathogenic yeast. J Med Vet Mycol 32, suppl. 1, 1-8.

Poulter, R. T. M. (1987). Natural auxotrophic heterozygosity in Candida albicans. Crit Rev Microbiol 15, 97-101.

Poulter, R. T. M. (1995). Genetics of Candida species. In The Yeast, vol 6, pp. 285-308. Edited by A. H. Rose, A. E. Wheals \& J. S. Harrison. San Diego, CA: Academic Press.

Poulter, R. T. M. \& Rikkerink, E. H. A. (1983). Genetic analysis of red, adenine-requiring mutants of Candida albicans. J Bacteriol 156, 1066-1077.
Poulter, R. T. M., Jeffery, K., Hubbard, M. H., Shepherd, M. G. \& Sullivan, P. A. (1981). Parasexual genetic analysis of Candida albicans by spheroplast fusion. J Bacteriol 146, 833-840.

Pujol, C., Reynes, J., Renaud, F., Raymond, M., Tibayrenc, M., Ayala, F. J., Janbon, F., Mallié, M. \& Bastide, J. (1993). The yeast Candida albicans has a clonal mode of reproduction in a population of infected human immunodeficiency virus-positive patents. Proc Natl Acad Sci USA 90, 9456-9459.

Riggsby, W. S., Torres-Bauza, L. J., Wills, J. W. \& Townes, T. M. (1982). DNA content, kinetic complexity, and the ploidy question in Candida albicans. Mol Cell Biol 2, 853-862.

Sarachek, A., Rhoads, D. D. \& Schwarzhoff, R. H. (1981). Hybridization of Candida albicans through fusion of protoplasts. Arch Microbiol 129, 1-8.

Scherer, S. \& Magee, P. T. (1990). Genetics of Candida albicans. Microbiol Rev 54, 226-241.

Silver, J. M. \& Eaton, N. R. (1969). Functional blocks of ad1 and ad2 mutants of Saccharomyces cerevisiae. Biochem Biophys Res Comm 34, 301-305.

Slutsky, B., Buffo, J. \& Soll, D. R. (1985). High-frequency switching of colony morphology in Candida albicans. Science 230, 666-669.

Stoldt, V. R., Sonneborn, A., Leuker, C. E. \& Ernst, J. F. (1997). Efg1p, an essential regulator of morphogenesis of the human pathogen Candida albicans, is a member of a conserved class of bHLH proteins regulating morphogenetic processes in fungi. EMBO J 16, 1982-1991.

Suzuki, T., Nishibayashi, S., Kuroiwa, T., Kanbe, T. \& Tanaka, K. (1982). Variance of ploidy in Candida albicans. J Bacteriol 152, 893-896.

Tsang, W. K. P., Cao, B. Y. \& Wang, J. (1997). Sequence analysis of Candida albicans phosphoribosyl-aminoimidazole carboxylase (ADE2) gene. Yeast 13, 673-676.

Whelan, W. L. \& Kwon-Chung, K. J. (1988). Auxotrophic heterozygosities and the ploidy of Candida parapsilosis and Candida krusei. J Med Vet Mycol 26, 163-171.

Whelan, W. L., Partridge, R. M. \& Magee, P. T. (1980). Heterozygosity and segregation in Candida albicans. Mol Gen Genet $180,107-113$.

Wickes, B. L. \& Petter, R. (1996). Genomic variation in C. albicans. Curr Top Med Mycol 7, 71-86.

Received 15 December 1998; revised 30 March 1999; accepted 6 April 1999. 